\title{
THE FUTURE FOR NUCLEAR POWER
}

$\mathrm{T}$ HE present strength of the United Kingdom in the field of commercial nuclear power is due very largely to the foresight and singleness of purpose which have always marked the activities of Sir Christopher Hinton. A paper by Sir Christopher having as its subject "The Future for Nuclear Power"* must therefore command the utmost respect. The argument presented in this Lecture is mainly concerned with the cost of electricity generated from nuclear power stations of existing design, the way in which the nuclear power industry will develop and the price at which it will be possible to generate nuclear power in the future.

As a starting point, Sir Christopher takes approximate figures for reactors of the type which have been ordered by the electricity authorities in the United Kingdom. These reactors which are now under construction are based on the Calder Hall design and use essentially the same materials. However, they are of larger size and their design has been optimized for power generation and not for the production of plutonium as at Calder Hall. The cost of power generation is made up in the following way when operating at 80 per cent load-factor :

$\begin{array}{lc} & \begin{array}{c}\text { Pence per kWh. } \\ \text { sent out }\end{array} \\ \text { Depreciation (5 per cent interest and 20 years life) } & 0.37 \\ \text { Interest on fuel charge (5 per cent) } & 0.06 \\ \text { Fuel replacement charge } & 0.24 \\ \text { Operating expenses } & \underline{0.06} \\ \text { Total } & 0.73 \\ \text { Credit for plutonium in irradiated fuel } & 0.07 \\ \text { Net cost } & \underline{0.66}\end{array}$

In this analysis the fuel cost is calculated on the basis of a figure of $£ 20,000$ per tonne of fabricated uranium in the form of complete fuel elements.

Two points call for special comment. It is to be noted that 65 per cent of the cost of electricity sent out arises from the capital charges in the case of these first nuclear stations. This is in contrast to a conventional coal-fired station where only about 25 per cent of the cost of electricity arises from these charges, but where the fuel cost is the major item. The second point to be noted is that the credit for by-product plutonium has been scaled down drastically from the level which was proposed at the time of publication of the original White Paper programme. The case for nuclear power resting on a substantial credit for plutonium production was never a very satisfactory one. Plutonium credit has now largely disappeared from the picture. Thanks to the successful engineering development of the gas-cooled reactor, however, it now seems reasonably certain that the cost of electrical power sent out from these first industrial stations, to be completed in 1960-61, will be only marginally higher than the cost of power produced from the best conventional stations completed at that date.

From this point Sir Christopher argues by analogy with the history of development of the coal-fired

* The Future for Nuclear Power. By Sir Christopher Hinton, on 15th March, 1957.) Pp. 20. (Stockholm: Royal Swedish Academ of Engineering Sciences, 1957.) steam engine that the capital cost per horse-power or per kilowatt is likely to follow an exponential law of decrease. In view of the large proportion of the total cost of generation represented by the capital component in the case of the nuclear stations, it is concluded that a large reduction in generating cost will be possible in successive designs with the passage of years.

A possible criticism of this argument from history is that historical analogies are apt to be misleading, and it may easily happen that unrelated phenomena may yield a straight-line 'law' when quantities are plotted on a logarithmic scale.

This criticism, however, is at least partly answered in the paper, ". . . we are not entitled to assume these reductions in capital cost purely by the analogies of history unless we can predict how they may come about, and to do this it is once more useful to look back at the history of other prime movers. More than anything else, the reduction in the cost of steam power plants has been linked with the rise in the initial temperature which it has been possible to achieve in the steam cycle". 'The argument is then developed in some detail with a discussion of some of the engineering and metallurgical developments which may be expected to lead to increased heat ratings and higher working temperatures in future designs of nuclear reactor.

There can be no doubt at all that there will be a general trend towards higher ratings and higher temperatures with nuclear stations as in the case of other types of generating plant. Just how far this trend can be predicted in a quantitative manner, however, is open to question. There is at least one basic difference between nuclear and conventional thermal power plant which may affect the validity of the analogy. In conventional stations where energy is released by the combustion of fossil fuels, we necessarily start at the top of the cycle with a relatively high combustion temperature. The source of heat or furnace, however, is mechanically simple. Progress with steam plant has been concerned mainly with achieving higher steam pressures and temperatures, and the most difficult problems have arisen at the high-temperature end of the turbine, where large stresses and mechanical complexity are encountered in a region of high temperature. With a nuclear reactor, on the other hand, while theoretically the heat may be released at almost any temperature we please, the reactor core or heat source is itself a complex piece of structural and mechanical precision engineering. Formidable problems are to be expected in the operation of nuclear reactor cores at very high temperatures. The chequered history of the attempts to develop the gas turbine in large sizes for power generation which have been made during the past decade, provides a warning of the scale of difficulty that must be expected if too rapid an advance is attempted towards high temperatures in association with plant of mechanical or structural complexity.

Having sounded this note of criticism, however, it is necessary for the reviewer to point out that Sir Christopher Hinton has exhibited an unerring 
instinct in the past for being right in his engineering judgments. He may very well be right again on this issue of the pace of development of nuclear plant towards higher working temperatures. That part of his paper which deals with the further development of the Calder Hall type of station is of the greatest interest. The British commercial designs of graphitemoderated gas-cooled reactor have already gained a commanding lead over rival American designs for liquid-cooled reactors. It now seems probable that the gas-cooled reactor may also prove superior in its capacity for future development. Certainly no responsible engineer or scientist could quarrel with Sir Christopher's statement that "the technology of design is advancing so quickly that manufacturing provision must be laid down on the basis of forecasts ; its provision cannot follow in the wake of technical development".

J. M. KAY

\section{OXIDATION OF PLANT PHENOLICS}

\section{INAUGURAL MEETING OF THE PLANT PHENOLICS GROUP}

$T^{\prime \prime}$

HE Plant Phenolics Group was inaugurated at a meeting held in the Department of Botany, University of Cambridge, on April 9. Dr. E. C. BateSmith, presiding, said that the idea of forming the Group originated from a succession of inter-laboratory symposia on tannins, hydroxyaromatic acids (seo Chem. istry and Industry, 478; 1956), etc., in plants, under the auspices of the Food Investigation Organization of the Department of Scientific and Industrial Research. These symposia attracted a diversity of interest not catered for by any single existing Society. The response received to the invitation to enrol in the Group is a clear indication of the need which is felt for an association to provide for these diverse interests. The enrolled membership numbers one hundred and twenty, and represents university laboratories, agricultural and forestry research institutions, food research laboratories, and various other industrial laboratories, in approximately equal numbers.

The objects of the Group were defined as "the advancement of the knowledge of the phenolic constituents of plants in respect of their function, biosynthesis, the effect on plant and animal physiology and pathology, and the application of such knowledge in industry and agriculture".

A provisional committee was elected as follows: Dr. E. C. Bate-Smith (Low Temperature Research Station, Cambridge); Dr. H. G. Harvey (British Food Manufacturing Industries Research Association, Leatherhead, Surrey); Dr. D. E. Hathway (British Leather Manufacturers' Research Association, Egham, Surrey); Dr. A. C. Hulme (Ditton Laboratory, Larkfield, Maidstone, Kent); Mr. W. W. Reid (Carreras Lirnited, Stanhope Road, London, N.W.1); Dr. E. A. H. Roberts (Indian T'ea Association, Lafone Street, London, S.F.1) ; Dr. T. Swain (Low Temperature Research Station, Cambridge); Mr. A. H. Williams (Agricultural and Horticultural Research Station, Long Ashton, Bristol). Dr. J. Friend (Low Temperature Research Station) was appointed honorary secretary of the committee, pro tem. (vice Dr. T. Swain, absent abroad).
The inaugural meeting was followed by a symposium on "The Oxidation of Plant Phenolics", with Dr. J. Barker (Cambridge) presiding.

In a paper on "The Oxidation of Phenols" Prof. R. D. Haworth (Sheffield) enumerated the several chemical mechanisms by which phenols may be oxidized. With persulphate or Fenton's reagent, hydroxyl groups may be added either in ortho- or para-positions ; these changes are often accompanied by shifts of $p$-methyl groups and elimination of $p$-aldehydic groups. Thus the oxidation of $p$ :cresol to form homogentisic acid. Elimination of hydrogen takes several forms: the production of $o$ - or $p$ quinones ; the formation of diphenyl derivatives or diphenyl ethers; or the formation of peroxides. The oxidation of gallate esters to ellagic acid is an instance of the first type. Slightly more complicated bimolecular oxidations lead to such compounds as Pummerer's ketone from $p$-cresol. The fusion of rings and the formation of $\mathrm{C}-\mathrm{C}$ bridges can also lead to the morphine and apomorphine skeletons from phenylisoquinoline.

The very common phenolic compounds derived from phenylpropylene can be oxidized in the sidechain to form bimolecular structures such as those found in the lignans. It seems highly probable that the group of substances known as ligning are built up on this plan. Oxidations involving rupture of an aromatic nucleus lead to the formation of tropolones such as purpurogallin, and compounds such as brevifolin carboxylic acid and chebulic acid may be formed as products of ellagic acid oxidation.

The paper on "The in vitro Oxidation of Plant Phenolics" by Dr. D. E. Hathway (British Leather Manufacturers Research Association) was concerned with the way in which such chemical mechanisms as those described by Prof. Haworth might be involved in the formation of the larger molecules found in plant tissues, and especially those found in tanning extracts. These are of two classes, the one based on gallic acid and its oxidation products, and the other based on eatechin-like substances and their condensa. tion products. Aerobic autoxidation of gallate esters leads to ellagic acid and humic acids, but oxidation catalysed by mushroom polyphenolase proceeds preferentially to ellagic acid. 'The coincidence in the recorded systematic distribution of gallic acid with that of ellagic acid suggests that in some cases at least the latter may arise by enzymic oxidation of the former.

Studies of the autoxidation of $d$-catechin and a number of methyl-substituted catechins by mano. metric and spectrophotometric methods confirm that the oxidation proceeds by way of a quinone stage, followed by intermolecular C -C linkage. The evidence suggests that the most likely linkage is between either the 6 or 8 carbon of one molecule and the 2 ' carbon of the second. Such 'head-to-tail' linkages might take place progressively leading to large molecules of a phlobatannin nature. Autoxidation and polyphenolase (tobacco and potato) oxidation of catechin gave polymers which had the same elementary analy. sis and physical properties, and were closely similar in these respects to phlobutannins from Uncaric gaimbir (gambier) and Acacia catechu (cutch). Since both species contain catechin epimers, there is a strong supposition that the phlobatannins present in the tanning extracts are formed from catechins by oxidative condensation.

In dealing with "Polyphenolases as Respiratory Enzymes", Dr. W. O. James (Oxford) summarized the evidence in favour of the function of polyphonol. 